\title{
Influencing Factors of Rock Electrical Signal Analysis Based on Artificial Intelligence
}

\author{
Fei He, ${ }^{1}$ Jiabei Shen, ${ }^{2}$ Zhi Tang $\mathbb{D}^{3},{ }^{3}$ Xiaomeiao $Q i,{ }^{4}$ and Haoran $\mathrm{Li} \mathbb{D}^{5}$ \\ ${ }^{1}$ School of Applied Technology and Management, Liaoning Technical University, Fuxin 123000, Liaoning, China \\ ${ }^{2}$ Faculty of Electrical and Control Engineering, Liaoning Technical University, Fuxin 123000, Liaoning, China \\ ${ }^{3}$ School of Mechanics and Engineering, Liaoning Technical University, Fuxin 123000, Liaoning, China \\ ${ }^{4}$ Fuxin Innovation Extension Center for Industrial Technology (Fuxin Institute of Industrial Technology), Fuxin 123000, \\ Liaoning, China \\ ${ }^{5}$ School of Mining, Liaoning Technical University, Fuxin 123000, Liaoning, China \\ Correspondence should be addressed to Haoran Li; lihaoran0329@126.com
}

Received 17 August 2021; Revised 23 September 2021; Accepted 4 October 2021; Published 21 October 2021

Academic Editor: Sang-Bing Tsai

Copyright $(9) 2021$ Fei He et al. This is an open access article distributed under the Creative Commons Attribution License, which permits unrestricted use, distribution, and reproduction in any medium, provided the original work is properly cited.

To get the generation mechanism and influence factors of the coal-rock electrical signal, it provides a reference for coal-rock electric signal prediction and dynamic disaster. Firstly, the law of charge energy relation is deduced by using the universal or functional relation of Newton's law, and then coal and rock mass with different properties such as coal, granite, and sandstone are selected. Using the established test system, the influence of coal and rock electric signal is analyzed from the coal-rock temperature, coal and rock properties, coal-rock friction, coal-rock loading speed, and coal-rock load size. The chief results can be summarized as follows: in the process of coal-rock rising with temperature, the change rule of electrical signals can be divided into three stages according to the strength of electrical signals generated. The amplitudes of electrical signals generated by uniaxial compression of coal-rock mass with different properties are obviously different. Electrical signals can be generated during the friction of coal and rock. With the augment of loading speed, the electrical semaphore generated when the coal rock is about to fracture tends to be enhanced. The size of the electrical signal is not proportional to the size of the load, but the electrical signal is greatest when the rupture is imminent. The analysis of the influence factors of coal and rock electrical signals can provide a reference for the research on the generation mechanism of coal-rock electrical signals.

\section{Introduction}

The coal industry is one of the industries with more serious casualties in China's industrial production. The casualties in deep mining are more serious than those in shallow mining. The coal resources buried below 1000 meters in China account for about $53 \%$ of the total coal resources. Deep exploit is a necessary trend in the development of the coal industry. The composition and structure characteristics, deformation and failure characteristics, and energy accumulation and release characteristics of coal and rock mass in the deep are distinctly different from those in the superficial, which is more likely to induce coal-rock dynamic disasters such as rock burst [1]. For example, in 2017, the "1.4" coal and gas outburst accident occurred in Xingyu, Dengfeng, Henan Province; "11.11" rock burst accident in Liaoning Red Yang three mines; " 8.6 " coal and gas outburst accident in Xinmuga, Panzhou, Guizhou, in 2018; Shandong Longyun "10.20" impact of ground pressure accident, in 2019; Jilin Longjiabao "6.9" burst ground pressure accident; 12.17 coal and gas outburst accident in Guanglong, Anlong, Guizhou; Shandong Longgu in 2020 " $2 \cdot 22$ " accident [2, 3], and so on. Coal and rock dynamic disasters can cause serious underground damage and a large number of casualties, which brings great threat to people's life, property, and production safety. Therefore, it is pressing to further improve the effectiveness of coal and rock dynamic disaster prevention and control technology. 
At present, the main method of coal-rock dynamic disaster prediction is the drilling cuttings method [4], acoustic emission monitoring [5], electromagnetic radiation monitoring [6-8], seismic method [9], and so on. The cuttings method is mainly carried out in the working face, which will affect the normal advancement of the working face. The reliability is related to the technical proficiency of the operator, so continuous monitoring cannot be realized. Acoustic emission technology is subject to interference. Electromagnetic radiation technology is an important prediction method for dynamic disasters of coal rock, and the premise of electromagnetic radiation of coal rock is charge separation, but the charge separation of coal and rock does not necessarily have electromagnetic radiation, indicating that the relationship between electrical signals and deformation and fracture of coal and rock is more direct. In terms of seismic methods, although microseismic monitoring equipment was introduced earlier and a lot of research work has been done, a monitoring and early warning system has not been formed and most of them are recorded after the event and cannot be predicted.

En-Yuan et al. [10] concluded that the coal rock can generate surface potential when it is fractured under load, and the surface potential is in good consistency with the load. Ponomaryov [11] studied the charge variation of rock samples during fracture under uniaxial cyclic loading. The electrostatic induction method was adopted by Wang et al. [12], and it was observed that the charge amount of rock sample during compression and fracture was 10-8 10-6C. Kuksenko and Makhmudov [13, 14] loaded the marble and the induced charge can be measured by an electrometer. They found that the marble in the sudden loading and unloading of inductive charge sharply increased and then gradually attenuated. Kihiro et al. $[15,16]$ studied the surface charge phenomenon of granite under uniaxial compression and believed that positive charges were generated on the rock surface during loading. Zhao et al. [17] conducted an experimental study on the charge-induced signal and magnetic signal generated during the variant and fracture course of granite samples under uniaxial compression. It is concluded that electrical signals are generated continuously during rock variant and fracture, and the change is more obvious than that of magnetic signals. Compared with the magnetic signal, the electrical signal is less disturbed by the outside world and has a larger amplitude, which indicates that the charge induction method has more advantages in monitoring the precursors of rock deformation and fracture. He et al. and Liu [18-20] used AFM to test the microsurface potential and charge density of coal samples, and the microsurface showed certain typical characteristics at the nanometer scale. With the increase of coal sample metamorphism, the surface charge decreases first and then increases. He et al. [20-23] tested the change rule of coal current under uniaxial compression. It is concluded that the size of the current is related to the degree of load, and the current suddenly increases at the peak stress. Wang et al. [21-23] carried out a comparative analysis of charge in the uniaxial compression process of complete coal samples and prefabricated cracked coal samples, and the charge of prefabricated cracked coal samples appeared earlier. The prefabricated crack inclination angle is positively correlated with the horizontal charge amplitude in the poststress peak rupture stage. To obtain the charge evaluation index of impact voltage of deep coal seam, Xiaochun et al. [22-24] used briquette composed of roof, floor, and coal rock to carry out burst liability test and record the charge change in the process of rupture. The impact tendency index is proportional to the height in the combined briquette, and the change of charge is consistent with the trend of the stress change curve. The charge change rate after the peak of the combined briquette is proposed as the index to judge the impact voltage and verified in the field. Therefore, coal and rock electrical signals can be developed to predict coal and rock dynamic disasters $[25,26]$.

To predict coal and rock dynamic disasters based on coal and rock electrical signals, it is necessary to make clear the law of charge energy connection and the generation mechanism of coal and rock electrical signals in the breeding process of dynamic disasters. Existing research is not clear about the generation mechanism of coal and rock electrical signals, and it is believed that coal and rock electrical signals are mainly generated through the following reasons: under the action of nonequilibrium force, the nonuniform deformation of coal rock causes the charge migration and generates the free charge. The free charge is generated by friction between coal and rock particles. The temperature of the coal-rock friction surface increases and thermoelectron emission is formed. When coal crack propagates under load, it produces charge at the crack tip or on the primary surfaces on both sides of the crack. The defects (grain boundary, dislocation, and vacancy) in coal and rock mass under the action of external load, chemical bond fracture, dislocation slip, cavity diffusion, and so on, lead to charge separation. But there is only one mechanism of electric signal generation in the process of coal-rock deformation and fracture. Therefore, the study on the influence factors of coal and rock electrical signals can provide a reference for the research on the generation mechanism of coal and rock electrical signals and provide data for the prediction of coal-rock dynamic disasters by coal and rock electrical signals.

\section{Derivation of the Law of Charge Energy Relation}

2.1. Derivation from the Universality of Newton's Laws. The universality of Newton's second law shows that the external force in the law does not distinguish the character and source of the force. As long as the mass of the particle is certain, the magnitude and direction of the external force applied must be certain. No matter it is the tensile force of the human, the thrust of the internal combustion engine, the universal gravitation, or the electromagnetic force, the acceleration of the particle is the same. And, whether it is heaven or earth, the law of mechanics is the same. It can then be used to study everything from small charged particles and rocks to large objects and galaxies. The universality of the law 
essentially shows that the energy of various forms of motion of matter can be transferred to each other, and the effect of changing the state of motion is the same.

Then, two bodies of equal mass $M$ can be set apart by $r$, and the gravitational force between them can be

$$
F_{m}=-\frac{G M^{2}}{r^{2}}
$$

where $F_{m}$ causes both objects to accelerate $a_{1}=-\left(G M / r^{2}\right)$. Similarly, for $r$, two objects with positive and negative charges $\mathrm{Q}$, one object is fixed and the other object with mass $M$ can move, which is the interference Coulomb force:

$$
F_{e}=-\frac{K Q^{2}}{r^{2}},
$$

where $F_{e}$ causes another object of mass $M$ to accelerate $a_{2}=$ - $\left(k Q^{2} / M r^{2}\right)$.If $M$ and $Q$ are appropriately selected to make $a_{1}=a_{2}$, then $\left(G M / r^{2}\right)=\left(K Q^{2} / r^{2}\right)$. This is due to the universality of Newton's laws. Thus, we can acquire

$$
\xi=\frac{M}{Q}=\sqrt{\frac{K}{G}}=1.161195 \times{ }^{10}\left(\frac{\mathrm{kg}}{\mathrm{C}}\right) .
$$

Equation (3) shows that the gravitational force generated by mass $M$ and the Coulomb force generated by charge $Q$ cause an object of mass $M$ to obtain the same acceleration. Then, after a certain interval of time and space, object $M$ will get the same momentum and energy. Zeta can be said for the charge of equivalent quality. If $M$ and $Q$ are understood as the loss of mass and charge in a certain process, there are

$$
E=M C^{2}=\xi_{\mathrm{QC}^{2}} \text {. }
$$

Equation (4) is called the law of charge energy connection.

Newton's second law, the law of gravitation, Coulomb's law, and Einstein's law of the connection between mass and energy are all important fundamental laws built on solid experimental foundations. Then, equation (4) is also an equation based on existing experiments.

2.2. From a Functional Relationship. Faraday once thought that "there must be a connection between gravity and electricity." According to the origin of mass and charge and the origin between them and energy, we can think that there must be some relationship between mass and charge. The isolated mass system $M-m$ and the isolated charge system $Q-$ $q$ are, respectively, placed in an infinitely homogeneous and isotropic vacuum to form their standing wave fields which exist stably, such as the binary star system and the atomic system. When the distance $r$ of $M-m$ and $Q-q$ is set as $G M m / r^{2}=k Q q / r^{2}$ and just for convenience, let us call $q$ negative. Systems $M-m$ and $Q-q$ move conically around their center of mass under the action of inverse square gravity. When the field force generated by $M$ and $Q$, respectively, moves $m$ and $q$ from $r_{0}$ to $r$, the work done by $M$ and $Q$ on $m$ and $q$ is

$$
\begin{aligned}
& A_{1}=\int_{r_{0}}^{r} \vec{F} \bullet \vec{d} \vec{r}=\int_{r_{0}}^{r}-\frac{G M m}{r^{2}} d r=G M m\left(\frac{1}{r}-\frac{1}{r_{0}}\right), \\
& A_{2}=\int_{r_{0}}^{r} \vec{F} \bullet \vec{d} \vec{r}=\int_{r_{0}}^{r}-\frac{k Q q}{r^{2}} d r=k Q q\left(\frac{1}{r}-\frac{1}{r_{0}}\right) .
\end{aligned}
$$

Since $G M m=K Q q$, the work done by $M$ and $Q$ to $m$ and $q$ is equal; that is, $A_{1}=A_{2}$. So, the gravitational field and the electric field give $m$ and $q$ the same energy. The energy transfer is realized by the quantum of $M$ and $Q$ transmitting field and the quantum of $m$ and $q$ receiving field. According to the point of view that mass $M$ is the condensation of the gravitational field and charge $Q$ is the condensation of electromagnetic field, since isolated $M$ and $Q$ emit field quantum, their mass and charge will decrease; that is, $M$ and $Q$ will lose mass and charge when they do external work because they output energy. Let the force field of $M$ and $Q$ move $M$ and $Q$ to their respective relative distance $r$, respectively, and $M$ sends $\Delta m$ to $m$ and $Q$ sends tangent $\Delta q$ to $q$; then, according to the law of mass energy connection:

$$
A_{1}=\Delta E_{1}=\Delta m c^{2} \text {. }
$$

According to the force field generated by mass $M$ and charge $Q$ and the homology and symmetry of the physical law of motion of matter in this force field, it can be said that for the energy released or transmitted by a material system, the loss of mass and the loss of the electric quantity of the system are equivalent. So, there are

$$
A_{2}=\Delta E_{2} \propto \Delta q c^{2} .
$$

The proportionality constant $\xi$ is introduced to obtain $A_{2}=\xi \Delta q c^{2}$. As $A_{1}$ is equal to $A_{2}$, it has $\Delta m c^{2}=\xi q c^{2}$. The limit of both sides is obtained as follows:

$$
\xi=\frac{\mathrm{d} m}{\mathrm{~d} q},
$$

where $\xi$ is called charge mass equivalent, that is, both loss mass and loss charge are forms of energy transfer and transfer and are a measure of the energy released or transferred by the material system. Just as the thermal equivalent of $1 \mathrm{cal}=4.18$ joules, 4.18 joules of work applied to a thermodynamic system is equivalent to $1 \mathrm{cal}$ of heat transferred to the system to increase the internal energy of the system.

The definition of $\xi$ has been made above, and the value of $\xi$ is now calculated. Differentiate both sides of $G M m=K Q q$ to get

$$
G M \mathrm{~d} m+G m \mathrm{~d} M=k Q \mathrm{~d} q+k q \mathrm{~d} Q .
$$

Since the isolates $M$ and $Q$ sending $\mathrm{d} M$ and $\mathrm{d} Q$ are completely absorbed by $m$ and $q$, respectively, $\mathrm{d} M=-\mathrm{d} M$ and $\mathrm{d} Q=-\mathrm{d} Q$ can be obtained:

$$
\xi=\frac{\mathrm{d} m}{\mathrm{~d} q}=\frac{\mathrm{d} M}{\mathrm{~d} Q}=\frac{K(Q-q)}{G(M-m)} .
$$


Therefore, there is a linear function relationship for two isolated systems:

$$
M=\xi Q, m=\xi q
$$

And

$$
\xi=\frac{K(Q-q)}{G(M-m)}=\frac{K(Q-q)}{G\left(\xi_{Q}-\xi_{q}\right)}=\frac{K}{\xi_{G}} .
$$

There are

$$
\xi=\sqrt{\frac{K}{G}}=\sqrt{\frac{1}{4 \pi \varepsilon_{0} G}}=1.161195 \times 10^{10} \frac{\mathrm{kg}}{\mathrm{C}} .
$$

According to the law of mass and energy connection $E=M C^{2}$, we can get

$$
E=\xi q c^{2}
$$

The above equation is called charge energy relation law, and $q$ in the equation is the amount of charge lost by the material system in some process.

\section{Electric Signal Test}

3.1. The Test System. Data collector, electrical signal sensor, shielding system, press, temperature controller, and so on constitute the coal and rock electrical signal test system, as shown in Figure 1. The data collector has four channels for signal gather and to deal with processing, the resolution of analog-to-digital conversion is 16 bits, and the measurement accuracy of the system is up to $0.01 \%$. The $A / D$ change time is $1.25 \mu \mathrm{s}$, the sampling frequency can reach $250 \mathrm{kHz}$, and the signal sampling frequency in the test is set as $2500 \mathrm{~Hz}$.

\subsection{Test Procedure of Influence of Coal and Rock Temperature on Electrical Signal}

(1) Connect the instruments according to Figure 1(a), start the data collector, and turn on the heater.

(2) Electrical signal sensor and infrared thermometer, respectively, on the electrical signal and the temperature of coal and rock to the data collector, was made on the data collector temperature-electrical signal curve.

(3) Adjust the temperature of the heater from low to high by a temperature controller.

\subsection{Test Procedure of Influence of Coal Lithology on Electrical Signal}

(1) Connect each instrument according to Figure 1(b) and check the status of the experimental equipment.

(2) Adjust loading speed, the efficient data collection system is started, and the sampling frequency can be set to $2500 \mathrm{~Hz}$.

(3) Firstly start the press, and then open the sampling. At the end of the test, stop signal acquisition firstly, and then stop the press.
3.4. Test Procedure of Coal-Rock Friction Influence on Electrical Signal

(1) Connect each instrument according to Figure 1(c) and check the status of the experimental equipment.

(2) The efficient data collection system is started and the sampling frequency can be set to $2500 \mathrm{~Hz}$.

(3) Start the load-displacement recording system and choose the arguments of the load-displacement recording system: sensitivity, attenuation coefficient, output pattern, and so on.

(4) Firstly start the press, and then open the sampling. At the end of the test, stop signal acquisition firstly, and then stop the press.

\section{Test Results and Analysis}

Three coal-rock masses with different properties, such as coal, granite, and sandstone, are selected to analyze the influence of coal-rock electrical signals from the factors of coal-rock temperature, coal-rock property, coal-rock friction, and coalrock loading speed. Selection of coal as lean coal: granite is biotite granite, and the main mineral composition is quartz, feldspar, biotite, hornblende. The sandstone is quartz sandstone, and its chemical composition is mainly silica.

4.1. Influence of Coal Temperature on Electrical Signal. Two kinds of coal-rock with different properties, such as granite and sandstone, were selected to carry out experimental research on coal-rock electrical signals at different temperatures. The relation diagram of some coal-rock electrical signals and coal-rock temperature obtained is shown in Figure 2. The normal temperature of the rocks is $23^{\circ} \mathrm{C}$.

The following can be obtained from Figure 2:

(1) Granite starts to generate electrical signals when it is heated to about $60^{\circ} \mathrm{C}$, and sandstone starts to generate electrical signals when it is heated to about $30^{\circ} \mathrm{C}$.

(2) In the process of granite with temperature rise, the changing rule of the electrical signal can be divided into three stages: when the temperature is less than $60^{\circ} \mathrm{C}$, granite creates weak electrical signals with temperature rise; when the temperature of granite is less than $180^{\circ} \mathrm{C}$ and greater than $60^{\circ} \mathrm{C}$, the electrical signal increases slowly with the temperature increasing; and when the temperature of granite is greater than $180^{\circ} \mathrm{C}$, electrical signals increase faster with temperature.

(3) Sandstone with the temperature rising process, the electrical signal can be divided into three stages: the change rule of sandstone when the temperature is less than $50^{\circ} \mathrm{C}$, creates weak electrical signals with temperature rise. When the temperature of sandstone is less than $150^{\circ} \mathrm{C}$ and more than $50^{\circ} \mathrm{C}$, the electrical signal increases slowly with the increase of temperature. When the temperature of sandstone is greater than $150^{\circ} \mathrm{C}$, electrical signals increase faster with temperature. 


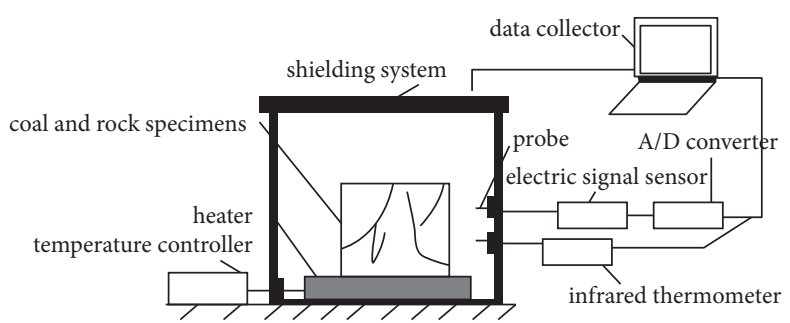

(a)

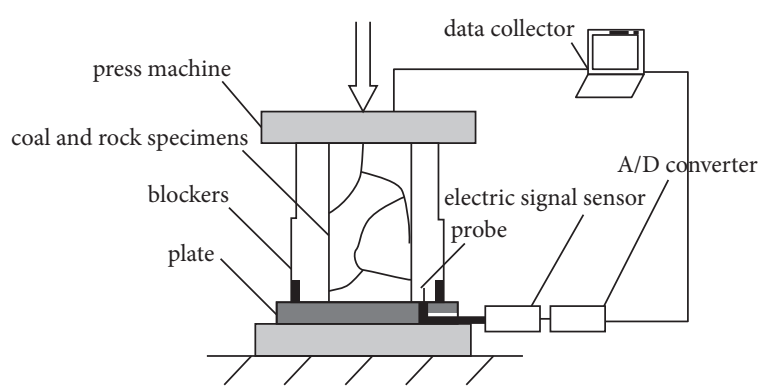

(b)

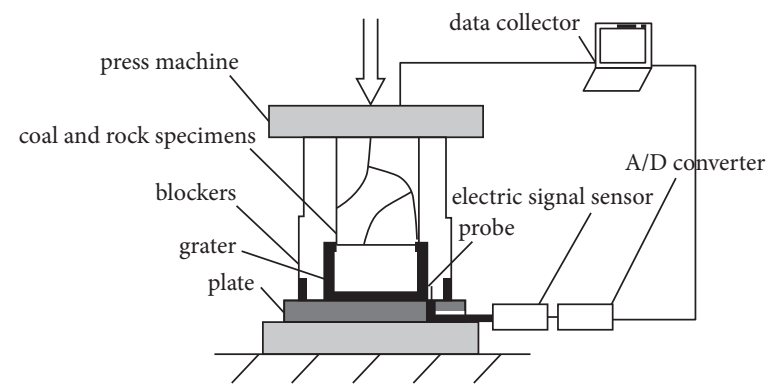

(c)

Figure 1: System diagram. (a) Schematic diagram of influence system of coal and rock temperature on the electrical signal. (b) Schematic diagram of influence system of coal lithology on the electrical signal. (c) Schematic diagram of influence system of coal-rock friction on the electrical signal.

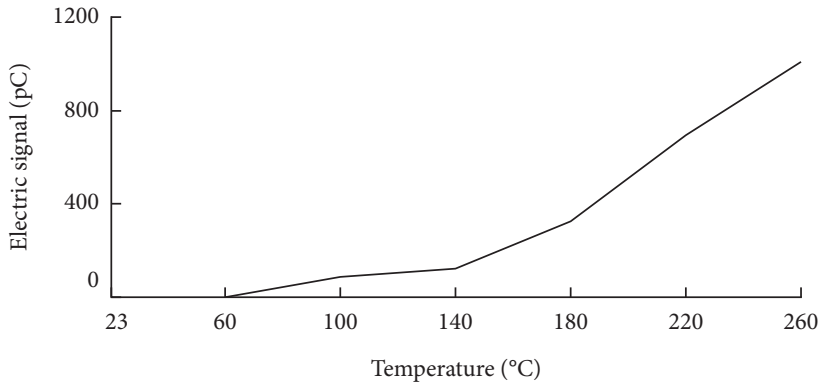

(a)

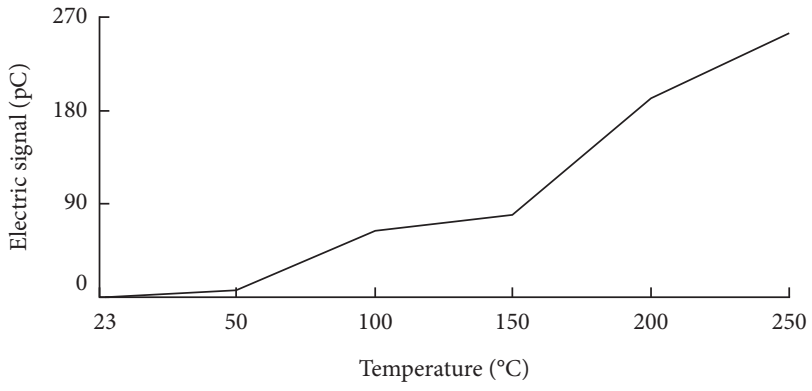

(b)

Figure 2: Change law curves of rock electrical signal vary with temperature. (a) Granite electrical signals with the temperature change rule curve change rule. (b) Sandstone electrical signals with the temperature curve.

(4) At the same temperature, the electrical signal produced by granite is stronger than that of sandstone.

\subsection{Influence of Coal Lithology on Electrical Signal.} Choose three kinds of properties of different coal-rock under uniaxial compression test and research, such as coal, granite, and sandstone; it is concluded that part of the electrical signals in the course of coal-rock compression diagram is shown in Figure 3.

In Figure 3, the compressive strength of coal is $11 \mathrm{MPa}$, that of granite is $96.4 \mathrm{MPa}$, and that of sandstone is $48 \mathrm{MPa}$. The following can be obtained from Figure 3:

(1) When coal and rock fracture is under uniaxial compression, the electrical signal is the largest. The maximum electrical signal of coal is 2200 PCS, that of granite is $4200 \mathrm{PCS}$, and that of sandstone is 1700 PCS.

(2) Under the condition of variant and rupture of coalrock under load, the maximum electric signal generated by granite is twice that of coal, and the maximum electrical semaphore produced by coal is half that of granite.

This shows that the electrical signal of coal and rock is related to the properties of coal and rock.

4.3. Influence of Coal-Rock Friction on Electrical Signal. The friction test of coal and rock mass with different properties, such as coal, granite, and sandstone, is carried out, and the electrical signal diagram of some coal and rock in the friction process is obtained, as shown in Figure 4.

The following can be seen from Figure 4: 


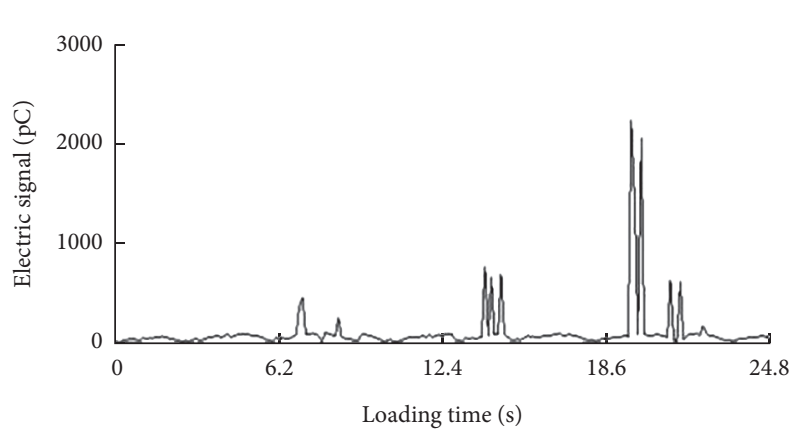

(a)

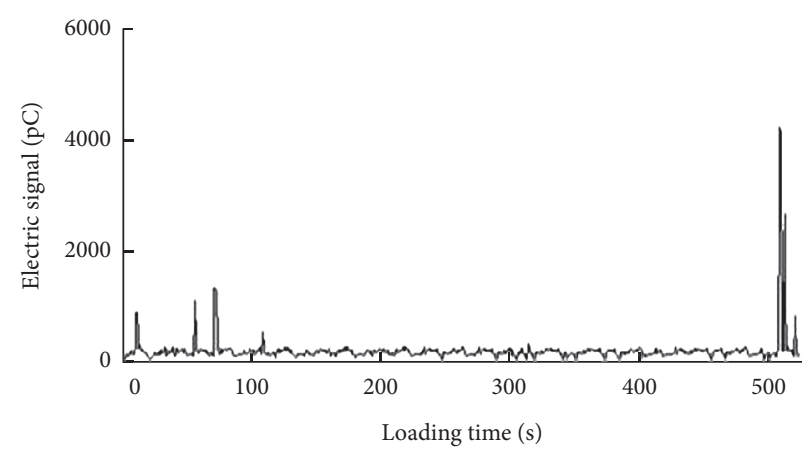

(b)

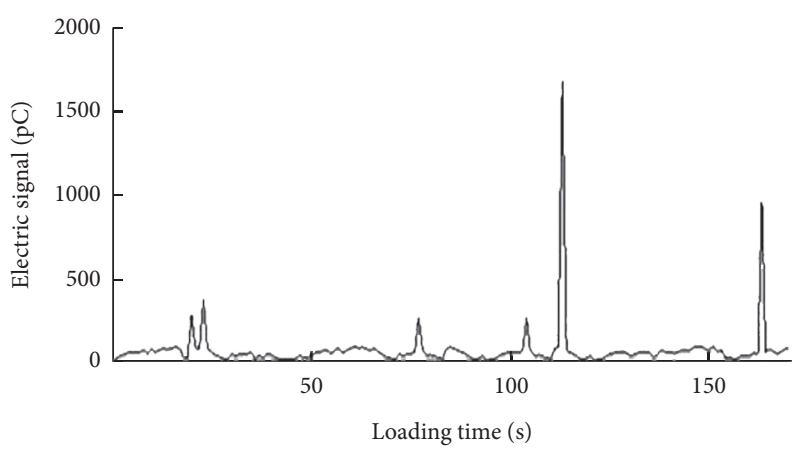

(c)

Figure 3: Rock electrical signal under uniaxial compression. (a) Coal power signal diagram under uniaxial compression. (b) Granite electrical signal diagram under uniaxial compression. (c) Electrical signal diagram of sandstone under uniaxial compression.

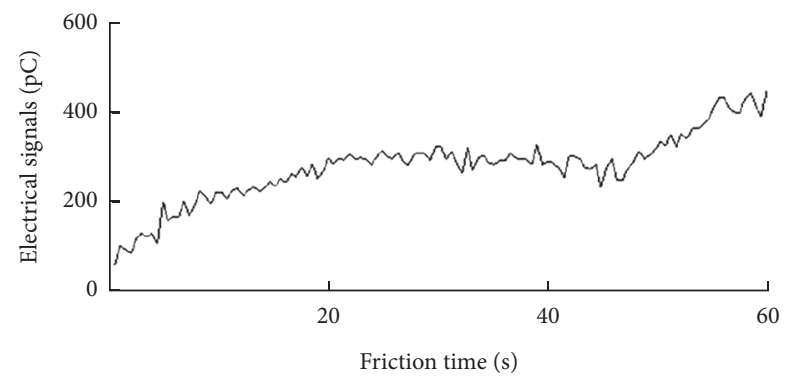

(a)

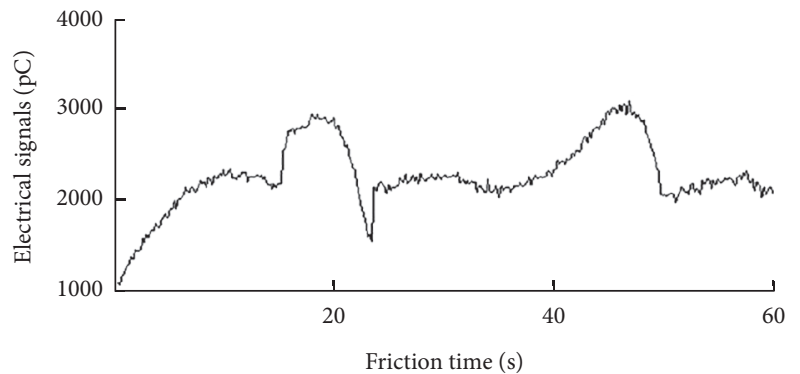

(b)

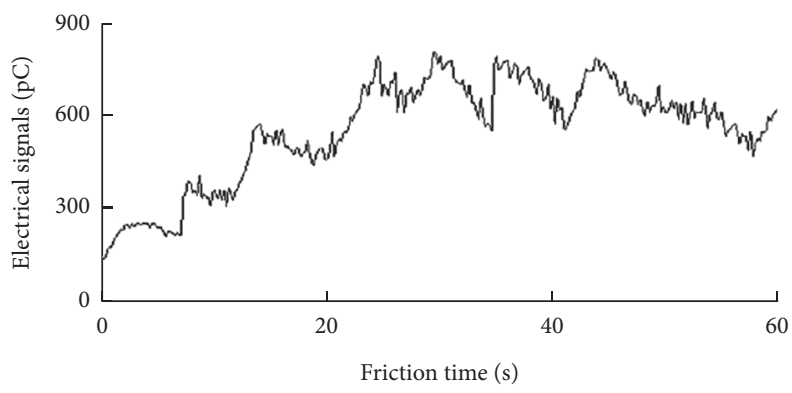

(c)

FIGURE 4: Electrical signal of rock friction. (a) Coal-power signal with friction time curve. (b) Granite electrical signal with friction time. (c) Sandstone electrical signal with friction. 


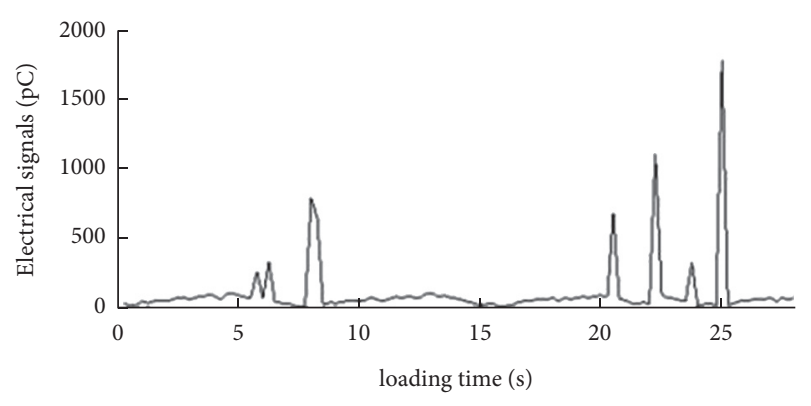

(a)

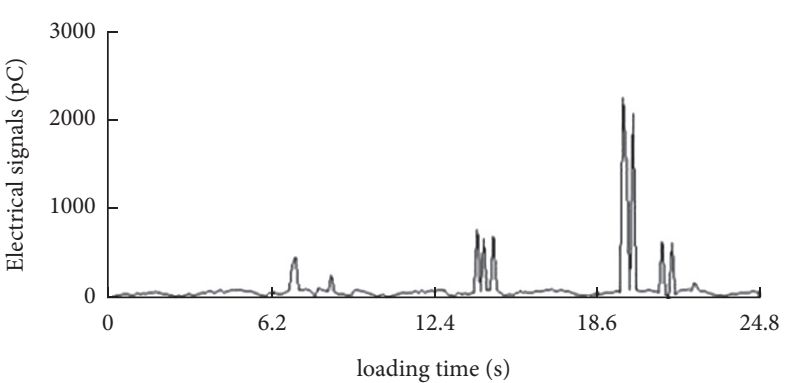

(b)

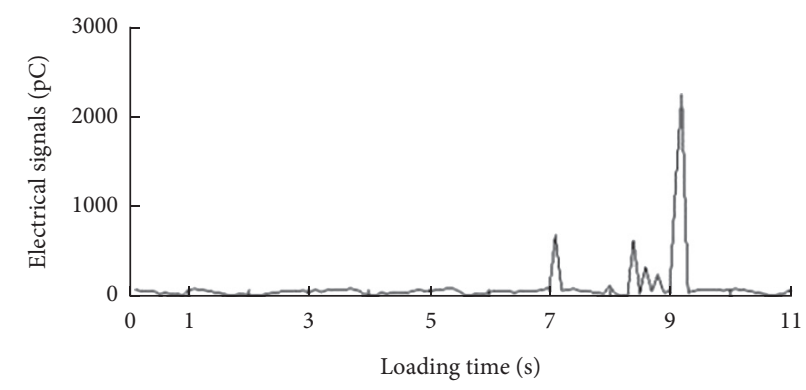

(c)

FIGURE 5: Electrical signal with different loading speeds. (a) $v=4 \times 10^{-6} \mathrm{~m} / \mathrm{s}$. (b) $v=6 \times 10^{-6} \mathrm{~m} / \mathrm{s}$. (c) $v=8 \times 10^{-6} \mathrm{~m} / \mathrm{s}$.

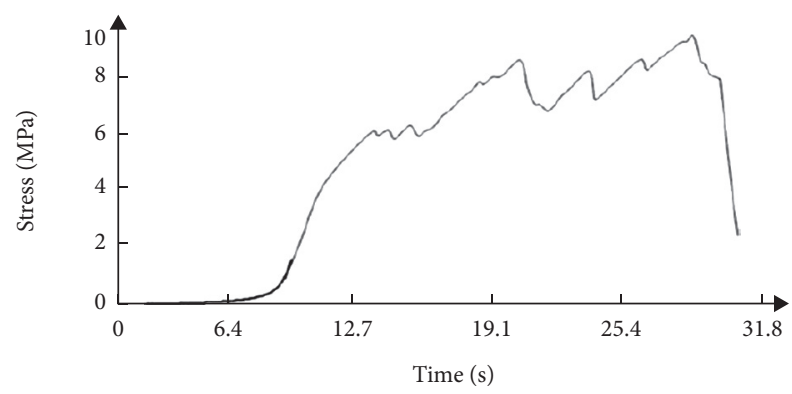

(a)

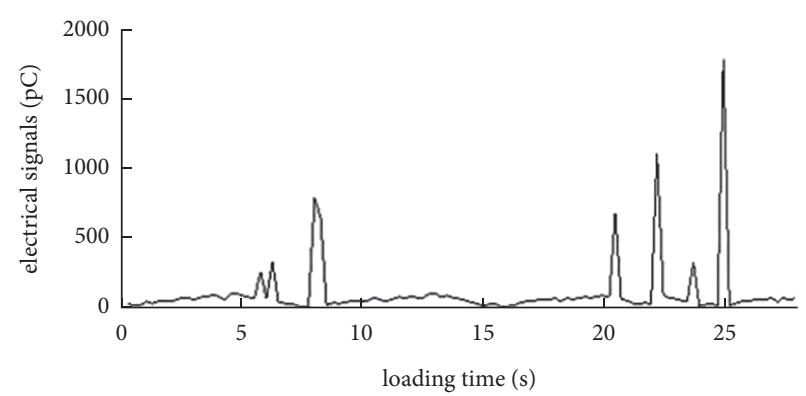

(b)

FIGURE 6: Rock electrical signal. (a) Loading time-stress curve of coal specimen. (b) Loading time-electrical signal curve of coal specimen.

(1) The electrical signals of coal, granite, and sandstone show two stages in the process of being rubbed. The electrical signals of coal and sandstone first increase with the increase of friction time. Later, with the increase of friction time, the electrical signal of coal rock tends to be stable.

(2) In the friction process of coal and rock, the electric signal generated by coal is about $300 \mathrm{pC}$, the electric signal generated by granite is about $2500 \mathrm{pC}$, and the electric signal generated by sandstone is about $650 \mathrm{pC}$.

4.4. Influence of Loading Speed on Electrical Signal. Choose three kinds of different properties of coal rock, such as coal, granite, and sandstone. An experimental study on the coal-rock charge under different loading rates shows that the electrical signal diagrams of some coals under loading rates of $4 \times 10^{-6} \mathrm{~m} / \mathrm{s}, 6 \times 10^{-6} \mathrm{~m} / \mathrm{s}, 8 \times 10^{-6} \mathrm{~m} / \mathrm{s}$, and so on, are shown in Figure 5.
In Figures 5(a)-5(c), the compressive strength of coal and rock, respectively, is $9.6 \mathrm{MPa}, 11 \mathrm{MPa}$, and $7.3 \mathrm{MPa}$.

The following can be seen from Figure 5:

(1) Loading speed is $4 \times 10^{-6} \mathrm{~m} / \mathrm{s}$, the compressive strength of 9.6 MPa coal specimen electrical signals generated in a burst of about 1800 PC. Loading speed is $6 \times 10^{-6} \mathrm{~m} / \mathrm{s}$, the compressive strength of $11 \mathrm{MPa}$ of coal specimen in a burst of electrical signals in about 2200 PC. Loading speed is $8 \times 10^{-6} \mathrm{~m} / \mathrm{s}$, the compressive strength of $7.3 \mathrm{MPa}$ coal specimen electrical signals generated in a burst of about 2200 PC.

(2) For coal and rock mass with the same properties, the electrical signal generated by coal-rock fracture increases with the augment of loading speed.

4.5. Effect of Loads on Electrical Signals. Electrical signals in the course of coal specimens increase in load change rule is shown in Figure 6. 
It can be seen from Figure 6 that the electric signal has a disproportionate relationship with the load. However, when the load is about to reach the compressive strength of coal, that is, when the coal specimen is about to crack, the electric signal is the strongest.

\section{Conclusion}

The following main conclusions are drawn from the analysis of the influence of coal rock temperature, coal rock properties, coal rock friction, coal rock loading speed, and coal rock load on electrical signal:

(1) There is a connection between charge energies. From the universality and function of Newton's laws, $E=\xi q c^{2}$.

(2) The temperature of coal rock affects the electrical signal of coal rock. In the process of coal-rock rising with temperature, the change law of electric signal can be divided into three stages according to the strength of electric signal generation, namely, the weak stage of electric signal increase, the slow stage of electric signal increase, and the fast stage of electric signal increase.

(3) Coal lithology has an influence on coal electrical signal. The size of the electric signal produced by coal-rock mass with different properties is obviously different. In the case of uniaxial compression, the electrical signals generated by coal-rock mass with different properties are the largest when a fracture occurs.

(4) The friction of coal and rock affects the electrical signal of coal and rock. Under certain conditions, the amplitude of the electric signal produced by friction between coal and rock with different properties is obviously different.

(5) loading speed of coal rock has an influence on the electrical signal of coal rock. With the increase of loading speed, the electrical signal generated by coalrock fracture tends to be enhanced. The size of the electrical signal is not proportional to the size of the load.

\section{Data Availability}

No data were used to support this study.

\section{Conflicts of Interest}

The authors state that this article has no conflicts of interest.

\section{References}

[1] Y. Pan, Z. Li, and M. Zhang, "Distribution, type, mechanism and prevention of rockbrust in China," Chinese Journal of Rock Mechanics and Engineering, vol. 22, no. 11, pp. 18441851, 2003.

[2] Coal Mine Safety Net, "Longgu, heze shandong mine burst 4 people died [EB/OL]," 2020, http://www.mkaq.org/html/ 2020/02/22/512755.shtml.
[3] Q. Qi, L. Yizhe, and Z. Shankun, "Seventy years development of coal mine rockburst in China: establishment and consideration of theory and technology system," Coal Science and Technology, vol. 47, no. 9, pp. 1-40, 2019.

[4] E. Y. Wang, The Effect of EME \&AE during the Fracture of Coal Containing Gas and its Application, China University of Mining and Technology, Xuzhou, China, 1997.

[5] Y. Wang, X. He, and L. Dou, "Study on regularity and mechanism of acoustic emission and electromagnetic emission during fracture process of coal samples," Chinese Journal of Geophysics, vol. 50, no. 5, pp. 1569-1575, 2007.

[6] X. Liu, E.-Y. Wang, X. He, Z. Liu, E.-L. Zhao, and Y.-G. Wang, "Electromagnetic radi-ation laws of the stress distribution in working face," Journal of China Coal Society, vol. 32, no. 10, pp. 1019-1023, 2007.

[7] J. Wang, E. Wang, and W. Jianping, "Analysis of chaotic charac-teristics of time series of coal rock electromagnetic emission," Journal of Disaster Prevention and Mitigation Engineering, vol. 26, no. 3, pp. 300-304, 2006.

[8] E.-Y. Wang, X.-F. Liu, E.-L. Zhao, and Z.-T. Liu, "Study of electromagnetic characteristics of stress distribution and sudden changes in the mining of gob-surrounded coal face," Journal of China University of Mining and Technology, vol. 18, no. 1, pp. 1-5, 2008.

[9] L. Dou, Y. Jiang, and A. Cao, "Monitoring and pre-warning of rockburst hazard with technology of stress field and wave field in underground coalmines," Chinese Journal of Rock Mechanics and Engineering, vol. 36, no. 4, pp. 803-811, 2017.

[10] W. En-Yuan, L. Zhong-Hui, G.-T. Liu, Y.-N. Li, and X.-Y. Song, "Experimental study on surface potential effect of coal under load," Chinese Journal of Geophysics, vol. 52, no. 5, pp. 1318-1325, 2009.

[11] A. B. Ponomariov, "Electric phenomenon of deformation and fracture of rock," in Collected Works of Soviet Earthquake Prediction Research, M. A. Sadovskiy, Ed., Seismological Press, Beijing, China, 1993.

[12] L. Wang, S. Zhengjiang, and C. Huaran, "A research on electrification during rock fracturing," Geophysics Advance in China in the Eighties, Academic Books and Periodicals Press, Beijing, China, 1989.

[13] V. S. Kuksenko and K. F. Makhmudov, "Mechanically-induced electrical effects in natural dielectrics," Technical Physics Letters, vol. 23, no. 2, pp. 126-127, 1997.

[14] V. S. Kuksenko, K. F. Makhmudov, and A. V. Ponomarev, "Relaxation of electric fields induced by mechanical loading in natural dielectrics," Physics of the Solid State, vol. 39, no. 7, pp. 1065-1066, 1997.

[15] T. A. Kihiro, B. W. S. Lau, and T. F. Friedemann, "Current and surlace potential induced by stress-activated positive holes in igneous rocks," Physics and Chemistry of the Earth, vol. 31, pp. 240-2I7, 2006.

[16] W. Xiao-Ping, S. Xing-Jue, and G. Zi-Qiang, "Study on the electrification of granite samples under compression," Chinese Journal of Geophysics, vol. 33, no. 2, pp. 208-211, 1990.

[17] Y.-F. Zhao and Y.-H. Pan, "Study on the charge and magnetic signals of granite samples under uniaxial compression," Chinese Journal of Geological Hazard and Control, vol. 20, no. 3, pp. 132-137, 2009.

[18] X. He, D. Song, X. Liu, W. Wang, Z. Li, and H. Liu, "Microelectrical characteristics of coals with different metamorphic grade," Journal of China Coal Society, vol. 43, no. 9, pp. 2367-2375, 2018.

[19] X. Liu, Study on Microstructural Characteristics of Coal Surface and the Mechanism of Electromagnetic Radiation, 
China University of Mining and Technology, Beijing, China, 2018.

[20] M. He, L. I. Zhong-Hui, J. Liu, and Y.-J. Liu, "Experimental study on surface current of coal under uniaxial compression," Journal of China Coal Society, vol. 38, no. 6, pp. 966-969, 2013.

[21] G. Wang, Y. Pan, and X. Xiao, "Experimental study on the failure characteristics and charge law of coal samples with large scale single pre-crack," Journal of China Coal Society, vol. 43, no. 8, pp. 2187-2195, 2018.

[22] X. Xiaochun, J. Chen, X. Zhao, D. Xin, D. Lian-Peng, and $\mathrm{X}$. Jun, "Experimental study on the charge criterion of coalrock bodies burst tendency," Rock and Soil Mechanics, vol. 38, no. 6, pp. 1620-1628, 2017.

[23] W. Gang, P. Yishan, and X. Xiaochun, "Experimental study on influence of burst tendency on damage charge law of coal sample under loading," Coal Science and Technology, vol. 47, no. 11 , pp. 247-254, 2019.

[24] W. Gang, P. Yishan, X. Xiaochun, W. Di, D. Xin, and Z. Xin, "Experimental study on charge law of coal-rock bodies rock burst tendency and failure characteristics," Chinese Journal of Safety Sciences, vol. 26, no. 7, pp. 135-140, 2016.

[25] Z. Yixin, J. Yaodong, and Z. Jie, "Experimental study on precursory information of deformations of coal-rock composite samples before failure," Chinese Journal of Rock Mechanics and Engineering, vol. 27, no. 2, pp. 339-346, 2008.

[26] X. Xiaochun, F. Yufeng, and W. Di, "Study on relationship between mechanical properties and acoustic emission-charge signals of combined coal-rock," Journal of Safety Science and Technology, vol. 14, no. 2, pp. 126-132, 2018. 